\title{
Milk yield, milk composition and blood metabolites in organic sows on pasture winter and summer
}

- effect of two different dietary protein levels

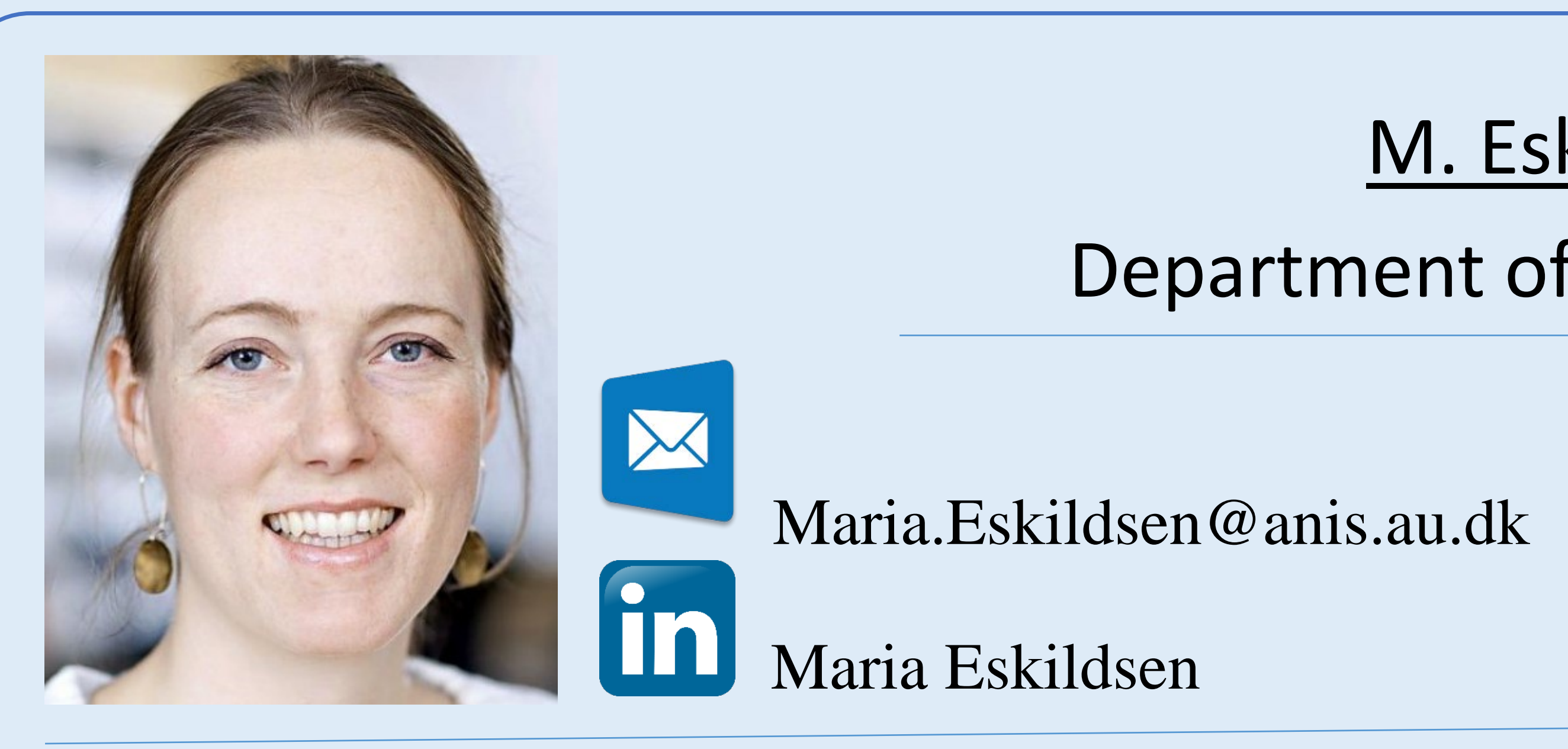

Why

Organic sows on pasture ingest a considerable amount of protein from grassing in summer and from silage in winter.

However, these contributions are normally not taken into account when formulating basal diets for organic sows, hence the animals might be oversupplied with protein with the current Danish feed recommendations.

A protein oversupply is an environmental challenge due to $\mathrm{N}$ leaching, costly to the farmer in terms of bought-in soy and the excess $\mathrm{N}$ might affect the energy utilization of organic sows negatively.

\section{Aim of this study}

To investigate the effect of reduced dietary protein level on the lactational performance of organic sows under Danish weather conditions and ad lib. access to clover grass during summer and grass silage during winter.

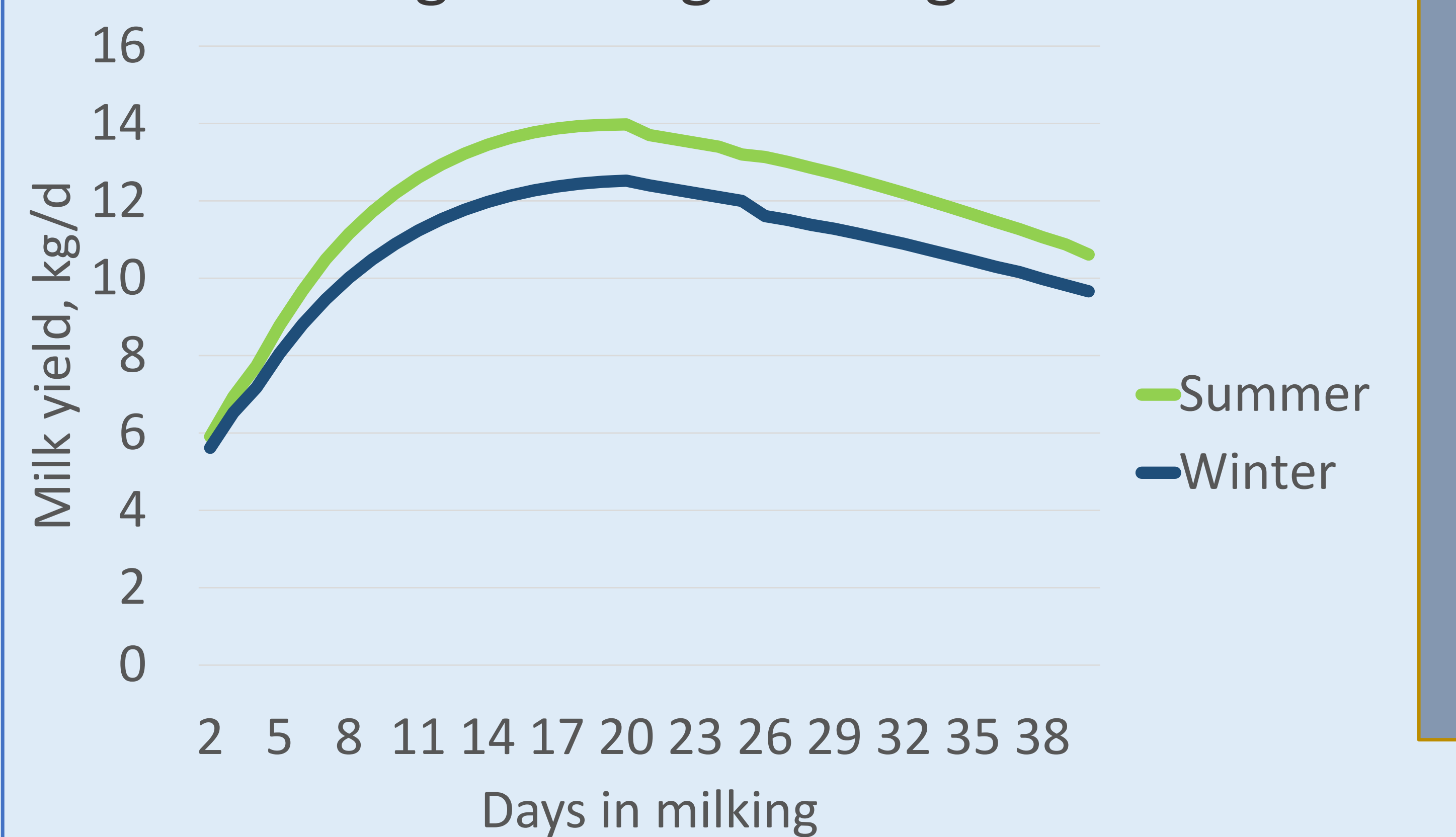

$-$$$
\text { P }
$$
protein
Diet Milk yield, $\mathrm{kg} / \mathrm{d}$ rotein protein \begin{tabular}{l} 
Litter ADG, \\
Milk comp \\
Dry mat \\
Protein, \\
Casein, \\
Lactose, \\
Fat, \% \\
\hline Energy, \\
\hline
\end{tabular} \section{2}

\begin{tabular}{|c|c|c|c|c|c|c|c|c|}
\hline & \multicolumn{3}{|c|}{ Diet } & \multicolumn{3}{|c|}{ Season } & \multicolumn{2}{|c|}{ P-value } \\
\hline & $\begin{array}{l}\text { Low } \\
\text { protein }\end{array}$ & $\begin{array}{l}\text { Normal } \\
\text { protein }\end{array}$ & SEM & Summer & Winter & SEM & Diet & Season \\
\hline tilk yield, kg/d & 12.1 & 12.3 & 0.36 & $13.7^{a}$ & $10.8^{b}$ & 0.36 & NS & $<.001$ \\
\hline tter size & 11.7 & 11.9 & 0.37 & $12.8^{a}$ & $10.8^{b}$ & 0.37 & NS & 0.001 \\
\hline tter ADG, Kg/d & 3.1 & 3.1 & 0.09 & $3.4^{\mathrm{a}}$ & $2.8^{b}$ & 0.09 & NS & $<.001$ \\
\hline illk compositior & & & & & & & & \\
\hline Dry matter, \% & 19.1 & 19.2 & 0.28 & $18.7^{b}$ & $19.6^{a}$ & 0.26 & NS & 0.02 \\
\hline Protein, \% & 5.2 & 5.4 & 0.08 & 5.3 & 5.3 & 0.08 & 0.10 & NS \\
\hline Casein, \% & $4.0^{b}$ & $4.2^{a}$ & 0.06 & 4.1 & 4.1 & 0.05 & 0.01 & NS \\
\hline Lactose, \% & 4.9 & 4.9 & 0.03 & 4.9 & 4.9 & 0.03 & NS & NS \\
\hline Fat, $\%$ & 8.4 & 8.4 & 0.28 & $8.0^{b}$ & $8.8^{a}$ & 0.26 & NS & 0.01 \\
\hline Energy, KJ/g & 5.24 & 5.31 & 1.10 & $5.10^{b}$ & $5.45^{\mathrm{a}}$ & 1.04 & NS & 0.01 \\
\hline
\end{tabular}

\section{- 47 organic LY sows \\ - $1^{\text {st }}$ parity: winter, $2^{\text {nd }}$ parity: summer}

- Two protein levels; $12.8 \%$ or $14.7 \%$ of DM

- Diets were iso-energetic; 14 MJ ME/d

- Summer; Ad lib access to clover grass

- Winter; Ad lib. access to grass silage

- Blood samples; Jugular vein puncture in early (d5), peak (d20) and late (d40) lactation

- Milk samples on d5, d20 and d40

- Sows and piglets individually weighed on d5, d20 and d40

- Milk analysis; infrared spectroscophy

- Milk yield estimation; Hansen et al. (2012)

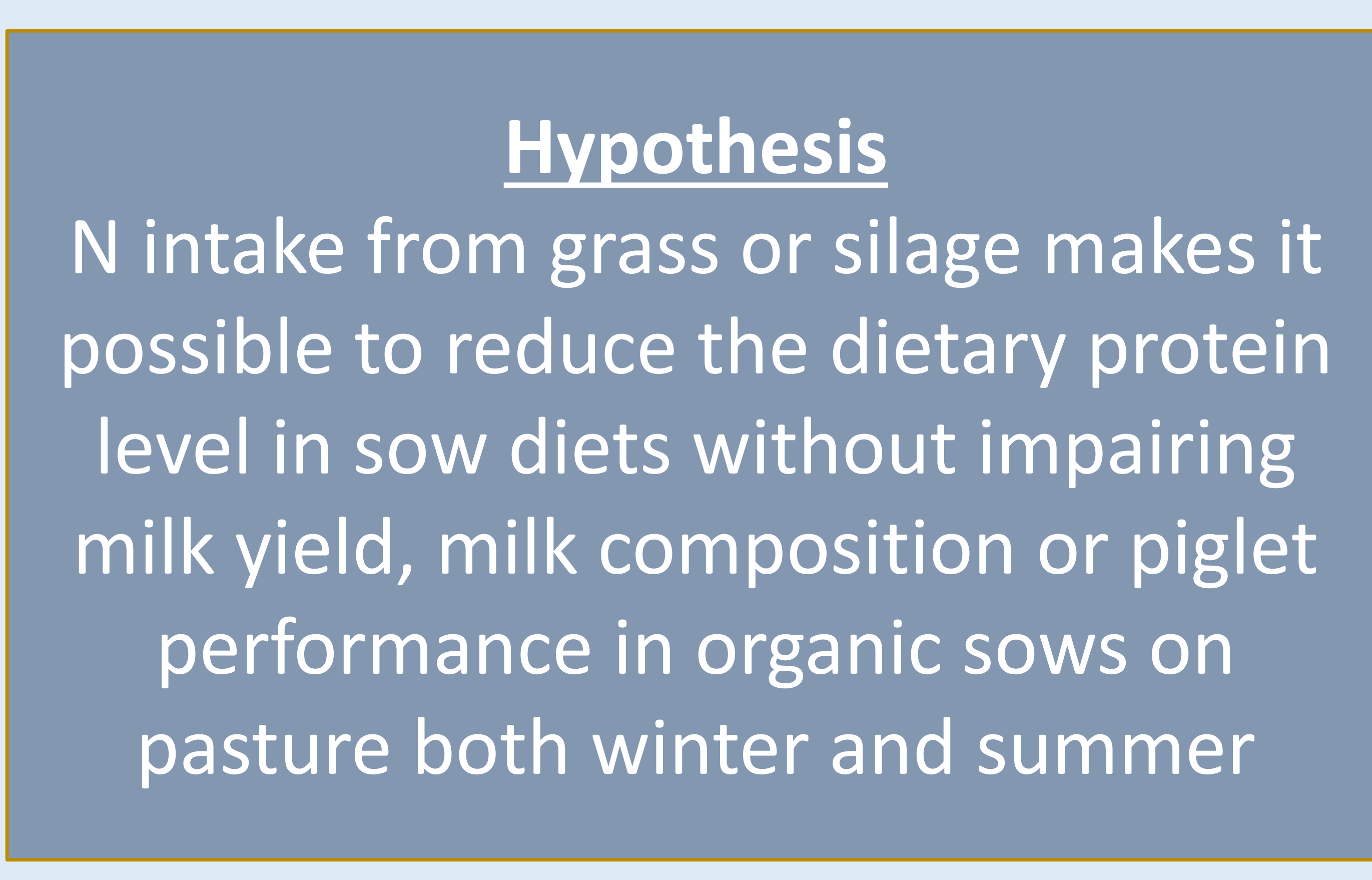

\section{Season}

\begin{tabular}{|c|c|c|c|c|c|c|c|c|}
\hline & \multicolumn{2}{|c|}{ Diet } & \multirow[b]{2}{*}{ SEM } & \multicolumn{2}{|c|}{ Season } & \multirow[b]{2}{*}{ SEM } & \multicolumn{2}{|c|}{ P-value } \\
\hline & $\begin{array}{c}\text { Low } \\
\text { protein }\end{array}$ & $\begin{array}{l}\text { Normal } \\
\text { protein }\end{array}$ & & Summer & Winter & & Diet & Season \\
\hline yield, kg/d & 12.1 & 12.3 & 0.36 & $13.7^{a}$ & $10.8^{b}$ & 0.36 & NS & $<.001$ \\
\hline size & 11.7 & 11.9 & 0.37 & $12.8^{a}$ & $10.8^{b}$ & 0.37 & NS & 0.001 \\
\hline ADG, $\mathrm{Kg} / \mathrm{d}$ & 3.1 & 3.1 & 0.09 & $3.4^{\mathrm{a}}$ & $2.8^{\mathrm{b}}$ & 0.09 & NS & $<.001$ \\
\hline composition & & & & & & & & \\
\hline y matter, \% & 19.1 & 19.2 & 0.28 & $18.7^{b}$ & $19.6^{a}$ & 0.26 & NS & 0.02 \\
\hline rotein, $\%$ & 5.2 & 5.4 & 0.08 & 5.3 & 5.3 & 0.08 & 0.10 & NS \\
\hline asein, $\%$ & $4.0^{b}$ & $4.2^{\mathrm{a}}$ & 0.06 & 4.1 & 4.1 & 0.05 & 0.01 & NS \\
\hline actose, $\%$ & 4.9 & 4.9 & 0.03 & 4.9 & 4.9 & 0.03 & NS & NS \\
\hline at, $\%$ & 8.4 & 8.4 & 0.28 & $8.0^{b}$ & $8.8^{a}$ & 0.26 & NS & 0.01 \\
\hline $\mathrm{rgy}, \mathrm{KJ} / \mathrm{g}$ & 5.24 & 5.31 & 1.10 & $5.10^{b}$ & $5.45^{\mathrm{a}}$ & 1.04 & NS & 0.01 \\
\hline
\end{tabular}

P. K. Theil

20, 8830 Denmark

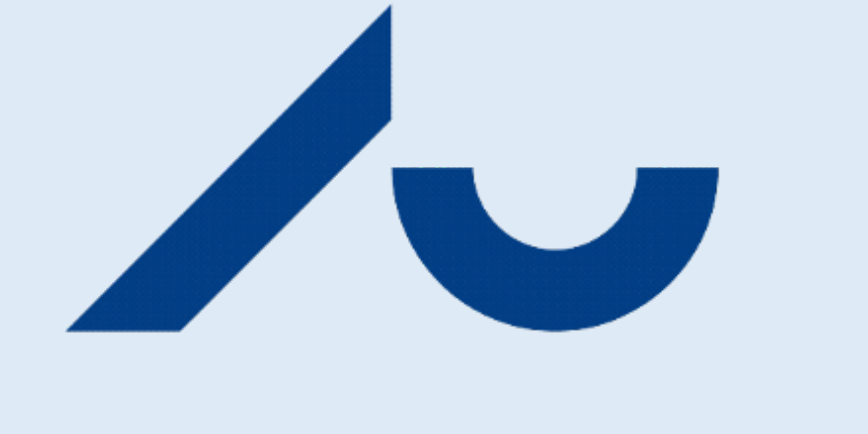

AARHUS UNIVERSITY

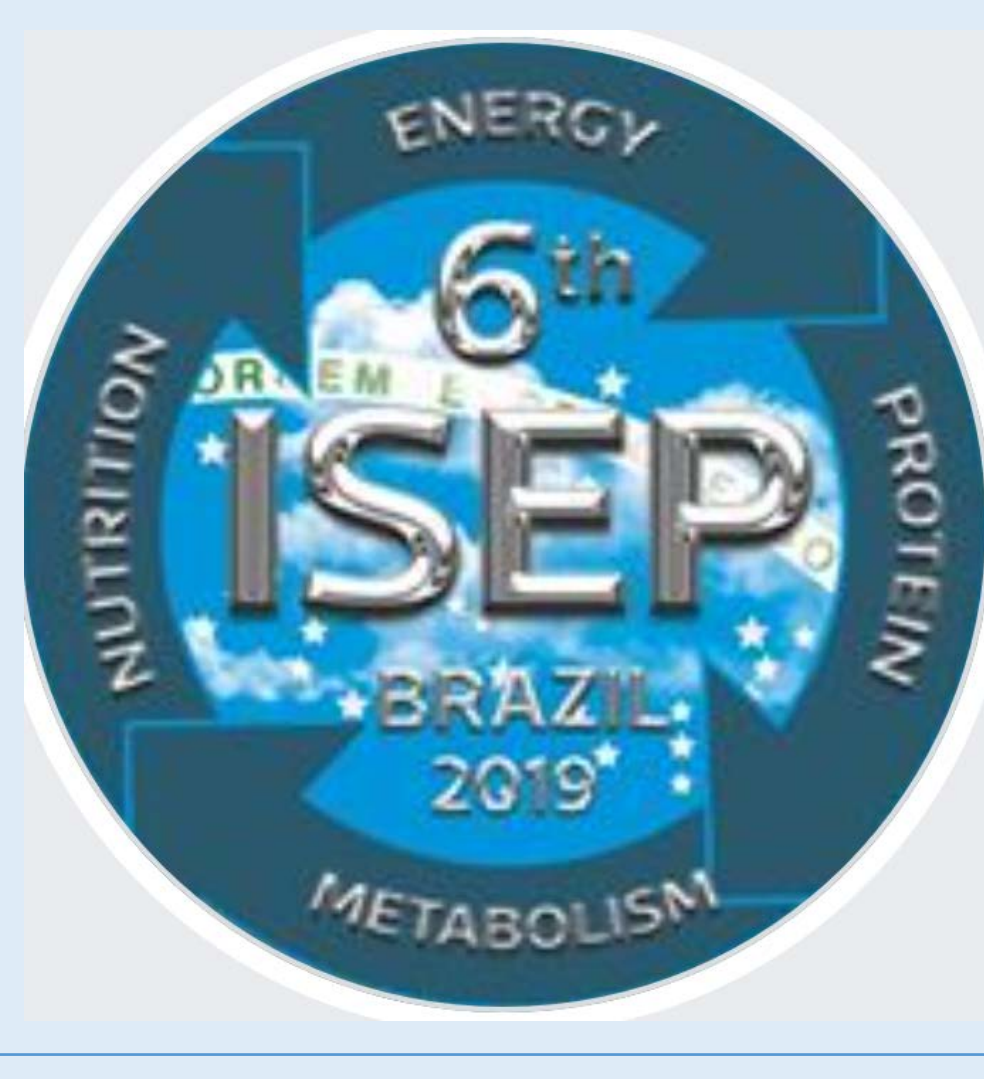

Diet effect:

\section{Main findings}

- Tendency to reduced milk protein in the low protein group $(\mathrm{P}=0.10)$

- $5 \%$ less milk casein in low protein diet $(P=0.01)$

No effect of $10 \%$ reduced protein level on:

- Milk yield, litter size or daily litter gain

- Milk composition: DM, lactose, fat, energy

- Plasma metabolites: creatinine, glucose, urea, lactate, triglyceride or NEFA

- Milk metabolites: Glu6P, glucose, uric acid, isocitrate, NAGase, LDH

Seasonal effect:

- $2.9 \mathrm{~kg}$ milk/d more in summer $(P<0.001)$

- 1.0 piglet more per litter in summer $(P=0.001)$

- 0.6 kilo higher litter gain/d in summer $(P<0.001)$

- $33 \%$ more lactate in plasma in winter $(P=0.003)$

- $5 \%$ more $D M$ in milk in winter $(P=0.02)$

- $10 \%$ more fat in milk in winter $(P=0.01)$

- $7 \%$ more energy in milk in winter ( $P=0.01)$

- Higher content of metabolites in milk in winter: Glu6P, uric acid, BHBA and NAGase $(\mathrm{P}<0.05)$

- Higher plasma creatinine in summer $(P=0.003)$ Season was confounded with parity in this study

\section{Conclusion}

Grass intake in summer and silage intake in winter allow at least $10 \%$ reduction of the dietary protein level in organic sows on pasture without impairing milk yield, litter size or milk composition

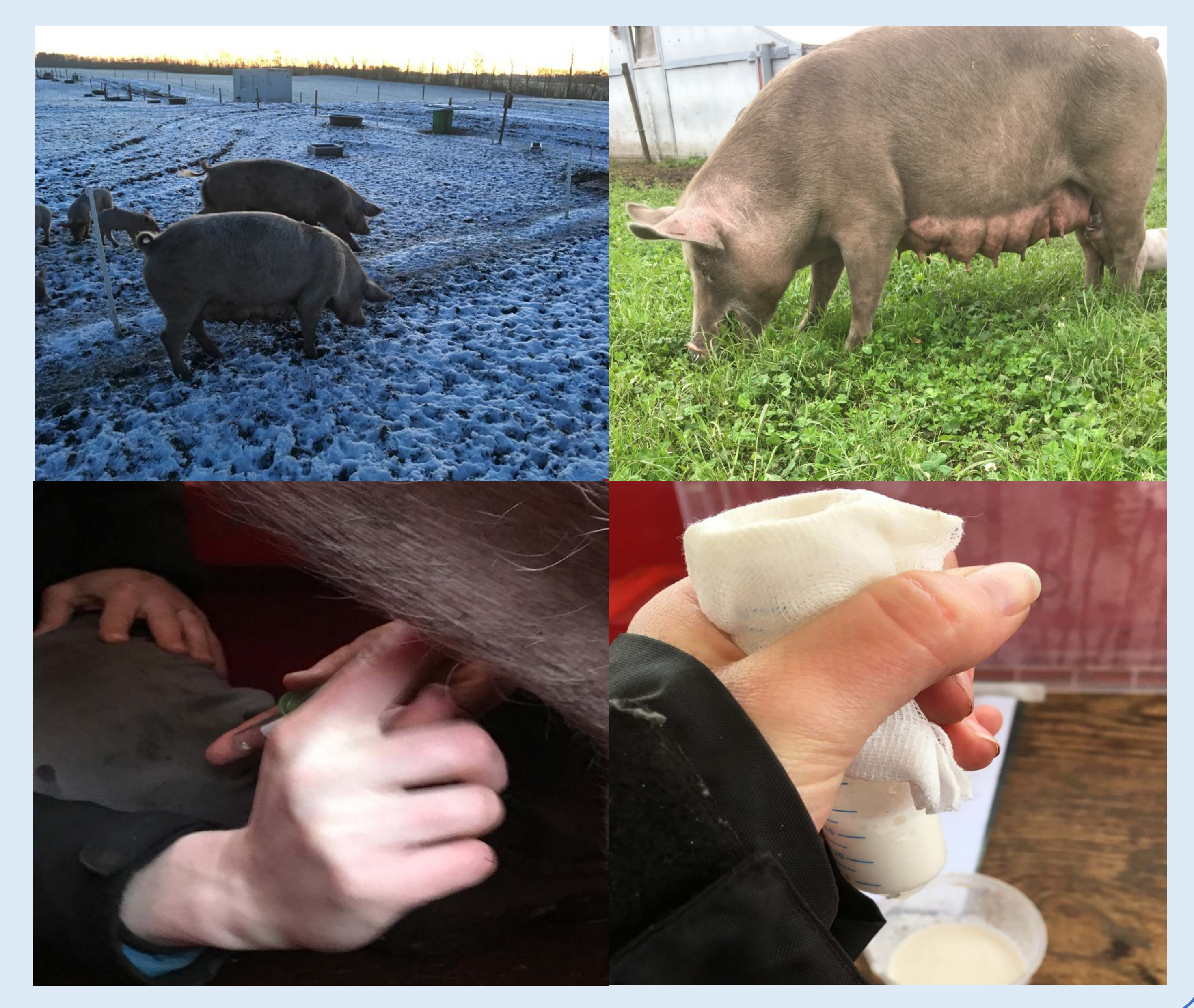

